\title{
Brunschvicg, Bergson e Meyerson: influências e contra-influências na filosofia de Bachelard
}

\author{
Gustavo Bertoche Guimarães ${ }^{1}$
}

\section{Introdução}

O pensamento de um filósofo não se constitui sozinho. Ele se organiza em torno de filiações e controvérsias - ou, em outras palavras, integra uma escola de pensamento, e confronta contra outras escolas. É a partir dessas relações pedagógicas de simpatia e de oposição que um filósofo se posiciona nas suas circunstâncias. Com Bachelard não foi diferente: as relações de aproximação ou de afastamento do filósofo com interlocutores centrais da filosofia francesa do início do século XX ajudaram-no a estabelecer o seu lugar no ambiente acadêmico francês.

Bachelard ingressou no meio acadêmico como aluno de Léon Brunschvicg. A partir dessa posição, envolveu-se, a partir do final da década de 20 , nos debates do seu mundo intelectual. Esse envolvimento se deu não apenas com a publicação de livros e artigos quase sempre polêmicos, mas também pela participação em inúmeros congressos e encontros que contavam com a presença de filósofos, escritores e cientistas - como as reuniões da Société Française de Philosophie, por exemplo. Bachelard foi, assim, um filósofo que participou intensamente da vida acadêmica de sua geração.

De acordo com Cristina Chimisso (2001), Bachelard procurou construir uma imagem de um filósofo no sentido antigo, distante das exigências burocráticas da Academia; contudo, não podemos falar de Bachelard como um filósofo que se afasta do rebuliço da cidade, que se isola para pensar, como um Heráclito. Ainda que sonhasse com os campos da Champagne, Bachelard foi um filósofo da universidade moderna. Mesmo colocando-se contra a filosofia tradicional, Bachelard inequivocamente se coloca dentro da tradição filosófica.

Neste ensaio, apresentamos a relação de Bachelard com os seus principais interlocutores:

\footnotetext{
${ }^{1}$ Doutor em Filosofia pela UERJ e Professor adjunto na Faculdade de Educação e Letras da Universidade Iguaçú. Teresópolis, RJ. E-mail: gusbertoche@gmail.com
}

Periódico Horizontes - USF - Itatiba, SP - Brasil - e021045 
Brunschvicg, Bergson e Meyerson. Como ficará claro, Bachelard posiciona-se como filósofo a partir dessas interlocuções: em certo sentido, as influências que recebem não são mais importantes, na constituição de seu pensamento, do que as contra-influências.

\section{Bachelard autodidata?}

Bachelard teve sua formação filosófica e científica realizada, em grande medida, de modo autodidata. Como diz Dominique Lecourt,

quando passa, tardiamente, na agrégation em 1922, ensina física e química no collège de Bar-sur-Aube. Esses detalhes individuais, que poderiam ser anedóticos, têm interesse por fazer aparecer, de uma vez por todas, a liberdade relativa de Bachelard em relação à tradição filosófica dominante ${ }^{2}$ (LECOURT, 1974, p.19-20).

Olival Freire concorda com essa posição. Freire (1995) lembra que Bachelard, de modo autônomo, estuda a teoria da relatividade e a teoria quântica (e sobre esses campos de estudos escreve livros) numa época em que esses campos de estudo são praticamente ignorados no ensino universitário francês - com a importante exceção de La déduction relativiste (MEYERSON, 1925). Ademais, segundo Freire, a concepção de Bachelard a respeito da localização da matéria no espaço-tempo, formulada por Bachelard em Le nouvel esprit scientifique (BACHELARD, 1946),

antecipam, na nossa opinião, aspectos essenciais da teoria quântica (nãolocalidade quântica) já contidos no formalismo da teoria quântica, mas que só emergiram nos debates entre Einstein e Bohr, em 1935, e foram efetivamente esclarecidas nos debates, e testes experimentais, em torno de um resultado teórico apenas formulado em 1964, as chamadas Desigualdades de Bell; posteriormente, portanto, ao desaparecimento de Bachelard (FREIRE, 1995, p.43-44).

Esse pioneirismo e esse autodidatismo não significam, todavia, uma independência filosófica completa. Bachelard foi profundamente influenciado por outros filósofos de sua época.

\footnotetext{
2 “Iorsqu'il passa, tardivement, l'agrégation em 1922, il enseignait la physique et la chimie au collège de Bar-surAube. Ces détails d'histoire individuelle, qui pourraient être anecdotiques, ont l'intérêt de faire apparaître tout à la fois la relative liberté de Bachelard par rapport à la tradition philosophique dominante".
}

Periódico Horizontes - USF - Itatiba, SP - Brasil - e021045 
Será suficiente apontar três pensadores fundamentais, cada um representando a motivação para um aspecto de sua filosofia. Desses três filósofos que serão apresentados, o primeiro - Léon Brunschvicg (1869-1944) - exerceu uma duradoura influência no pensamento bachelardiano. Já os outros dois - Henri Bergson (1859-1941) e Émile Meyerson (1859-1933) - são exemplos de uma posição filosófica do não: são influências que levam Bachelard a formular uma perspectiva de negação, de oposição, e, portanto, de construção e de superação dialética.

\section{A influência de Brunschvicg}

A maior influência recebida por Bachelard é, indiscutivelmente, a de Léon Brunschvicg, que, junto com Abel Rey, orientou o doutorado de Bachelard. Como diz Jean Wahl a respeito de Bachelard, "podemos considerá-lo, em primeiro lugar, como aquele que continuou, ainda que renovando em muitos pontos, o ensino de Léon Brunschvicg" (WAHL, 1962, p.164). Teresa Castelão também afirma que, em vez de acompanhar uma "metafísica positiva" bergsoniana, Bachelard teria seguido Brunschvicg, ao defender a importância da matemática como a linguagem por excelência do "novo espírito científico" (CASTELÃO-LAWLESS, 1997). Michel Vadée nota que Bachelard reconhece explicitamente a sua proximidade com Brunschvicg, em especial quanto à proposta de "reconstrução do criticismo" - reconstrução que reorganiza a distinção entre o idealismo e o realismo em novas bases (VADÉE, 1975).

Gary Gutting concorda que a concepção básica de ciência e de filosofia de Bachelard

deriva mais diretamente de Brunschvicg [...]. Como Brunschvicg, Bachelard vê a necessidade de a filosofia pôr em marcha o entendimento da razão por meio da reflexão sobre o desenvolvimento histórico da ciência; e, novamente como Brunschvicg, seu trabalho é baseado em estudos de casos na história da matemática e das ciências físicas ${ }^{3}$ (GUTTING, 2001, p.85-86).

Isso significa que, para Gutting, a influência de Brunschvicg sobre Bachelard não se limita

\footnotetext{
3 "derives most directly from Brunschvicg. [...] Like Brunschvicg, Bachelard sees philosophy as having to work out an understanding of reason by reflection on the historical development of science; and, again like Brunschvicg, his work is based on case-studies in the history of mathematics and the physical sciences".
}

Periódico Horizontes - USF - Itatiba, SP - Brasil - e021045 
ao objeto de estudo, mas também opera sobre o próprio método de pesquisa: o estudo de casos do progresso científico.

Para Cristina Chimisso, o aspecto crucial da influência de Brunschvicg sobre Bachelard consiste na concepção da dinâmica e da plasticidade da razão. Chimisso afirma que Bachelard perguntava-se como era possível que filósofos pudessem ainda continuar falando sobre frameworks fixos da inteligência e da razão após os trabalhos de Brunschvicg sobre o progresso e a transformação da mente (CHIMISSO, 2008). Efetivamente, Bachelard acompanha Brunschvicg na consideração de que a razão e o seu objeto transformam-se mutuamente.

Émile Bréhier descreve a filosofia de Brunschvicg como uma reação contra a tendência de abordar o pensamento e sua história a partir de uma perspectiva externa - tendência da qual Durkheim, por exemplo, participa. Para Bréhier, Brunschvicg "fez reentrar a inteligência na vida efetiva do espírito; o entendimento humano não é mais definido por um conjunto de categorias fixas"4 (BRÉHIER, 1950, p.52).

Em 1945, ano seguinte à morte de Brunschvicg, Bachelard publica, na Revue de Métaphysique et de morale (BACHELARD, 1972a), um pequeno texto em que afirma que "[I]er Brunschvicg, entender o mestre, é participar do espírito de finesse, é acima de tudo situar os problemas metafísicos em seu ponto sensível, é reconhecer a eficácia psicológico da reflexão filosófica" ${ }^{5}$ (BACHELARD, 1972a, p.169). Nessa reflexão filosófica, de acordo com Bachelard, “[p]ela ação decisiva de modificações bem sutis, ele sentiu bem que a doutrina de um a priori absoluto, imutável, estável, inflexível, não correspondia mais à informação científica. E Brunschvicg, assim, abandonou todo o partido das doutrinas kantianas" ${ }^{6}$ (BACHELARD, 1972a, p.172).

É inquestionável que a concepção de uma razão que se transforma dialeticamente, de uma razão desprovida de um a priori absoluto, é um dos princípios da filosofia de Brunschvicg herdados pelo pensamento bachelardiano. É por isso que Bachelard, em seu artigo, afirma, em

\footnotetext{
4 “il fait rentrer l'intelligence dans la vie effetive de l'esprit; l'entendement humain n'est pas defini par un ensemble de catégories fixes".

5 "[l]ire Brunschvicg, entendre le maître, c'est participer à l'esprit de finesse, c'est aller tout de suite au point sensible des problêmes métaphiysiques, c'est reconnaître l'efficacité psychologique de la réflexion philosophique"

6 "[p]ar l'action décisive de modifications si subtiles, il sentait bien que la doctrine d'un a priori absolu, immuable, stable, sans souplesse, ne correspondait plus à l'information scientifique. Et Brunschvicg avait ainsi abandonné toute une partie des doctrines kantiennes".
} 
tom de franca aprovação, que Brunschvicg propõe uma dialética entre "a medida e o medido", "o numerante e o numerado", "o determinante e o determinado", "o instrumento e o instrumentado" (BACHELARD, 1972a) - ou seja: os elementos dos polos do conhecimento se tornam mutuamente dependentes; eles se tornam complementares e mutuamente constitutivos e estão em permanente movimento oscilante.

Nesse sentido, Marcel Deschoux afirma que, para Brunschvicg, o pensamento “é invenção perpétua"7 (DESCHOUX, 1949, p.1): de acordo com Deschoux, a filosofia de Brunschvicg é uma "filosofia da razão, mas de uma razão viva, e criadora de suas próprias normas pela fecundação incessante de sua reação essencial com a experiência"8 (DESCHOUX, 1949, p.41). É, essencialmente, uma filosofia do progresso científico - assim como a filosofia das ciências de Bachelard.

Brunschvicg se posiciona mais especificamente a respeito da questão do progresso científico num opúsculo: La physique du vingtième siècle et la philosophie (BRUNSCHVICG, 1936), que é um desenvolvimento de uma conferência realizada em 10 de fevereiro de 1936 na Fondation hellénique de la cité universitaire de Paris. Esse escrito, um dos últimos publicados por Brunschvicg ${ }^{9}$, é particularmente interessante porque trata da questão fundamental da qual se originam as reflexões originais de Bachelard: a questão da ciência contemporânea.

Nesse texto, Brunschvicg afirma que os métodos da ciência diferem daqueles do conhecimento da vida comum, pois os problemas abordados em um caso e em outro são distintos (BRUNSCHVICG, 1936). Para Brunschvicg, a "natureza" que "as crianças e os povos infantis" (BRUNSCHVICG, 1936) têm como realidade não é, efetivamente, a realidade que se possui na idade adulta. Para que se possa receber essa realidade adulta, não basta somente enriquecer os detalhes da percepção do real sensível: é preciso fazer, em lugar disso, um "esforço heroico de conversão" (BRUNSCHVICG, 1936). Do mesmo modo, é fácil abordar a ciência

\footnotetext{
7 "est invention perpétuelle".

8 "philosophie de la raison, mais d'une raison vivante, et créatrice de ces propres normes par la fécondation incessante de son rapport essentiel à l'expérience".

${ }^{9}$ De acordo com a lista de toda a obra publicada de Brunschvicg disponibilizada por Marcel Deschoux (1949), a partir de 1932-1934 a produção do filósofo diminui expressivamente; os últimos textos publicados em vida por Brunschvic são de 1938. Yvon Belaval lembra que, com a queda da França perante a Alemanha na II Guerra Mundial, Brunschvic, perseguido pelo nazismo, abandonou Paris e viveu seus últimos anos escondido, até morrer em 1944 (BELAVAL, 2007, p.371-373).
}

Periódico Horizontes - USF - Itatiba, SP - Brasil - e021045 
apontando as similitudes entre as concepções científicas sobre o macrouniverso e sobre o microuniverso; mas esse gesto de apontá-las não corresponde, efetivamente, à prática dos cientistas.

Segundo Brunschvicg, até o fim do século XIX seria possível, ao filósofo, aproximar o mundo da vida comum com o mundo da ciência; a teoria do conhecimento kantiana apresentava uma solução adequada para ambas as instâncias epistemológicas. Contudo,

no fim do século XIX, a filosofia da física sofria daquilo que se poderia chamar uma crise de falência, que trouxe um estado geral de 'semi-ceticismo' em relação aos métodos e às verdades nos quais as gerações precedentes acreditavam estar assentada a nossa civilização. A falência da ciência, lugar comum dos ignorantes, parece ter sido declarada e ratificada pelos cientistas mais autorizados ${ }^{10}$ (BRUNSCHVICG, 1936, p.14).

Para Brunschvicg, no fim do século XIX surgem experiências e noções que não mais correspondem à epistemologia de acordo com a qual a ciência e o conhecimento comum seguem os mesmos princípios; descobre-se, com surpresa, que tanto a filosofia (via Nietzsche) quanto a ciência (por meio de descobertas que contrariavam o paradigma ${ }^{11}$ mecanicista) contêm uma escandalosa irracionalidade. Com isso, instaura-se uma crise entre a ciência e a filosofia.

Todavia, "as pretensas crises, que correspondiam aos maravilhosos progressos da astronomia e da microfísica, nos esclareceram e nos instruíram mais do que nos obscureceram e surpreenderam"12 (BRUNSCHVICG, 1936, p.27). Essas pretensas crises nos conduzem à rejeição não da razão científica, mas da razão metafísica que se crê uma "razão pura". A "razão pura" é substituída por uma "razão fina", diante de uma "experiência fina", que recusa a aparência imediata, a "experiência que se crê pura" (BRUNSCHVICG, 1936).

Em suma, a tese de Brunschvicg em La physique du vingtième siècle et la philosophie é a

\footnotetext{
10 "à la fin du XIXe siècle, la philosophie de la physique souffrait de ce que l'on pourrait appeler une crise de facilité, qui avait amené un état général de 'demi-scepticisme' vis-à-vis des méthodes et des vérités auxquelles les générations précédentes avaient demandé de soutenir l'assise de notre civilisation. La faillite de la science, lieu commun des ignorants, semblait avouée et ratifiée par les plus autorisés des savants".

${ }^{11}$ Aqui, a referência óbvia é KUHN (2000). Utilizamos o termo paradigma sem escrúpulos porque parte essencial da tese de Kuhn em sua obra clássica corresponde, embora com outra terminologia, a ideias que podem ser encontradas em Bachelard. Pode-se fazer uma correlação bastante estreita, por exemplo, entre a ciência revolucionária de Kuhn e a ruptura epistemológica de Bachelard.

12 “les prétendues crises, qui correspondraient aux merveilleux progrès de l'astronomie et de la microphysique, nous éclairent et nous instruisent plus qu'elles ne nous éblouissent et ne nous étonnent".
} 
de que a filosofia precisa abandonar a especulação metafísica (sobre os a priori kantianos, por exemplo), e se dirigir na direção da compreensão, via ciência, da conexão necessária entre a razão e a experiência. É preciso compreender a capacidade de transformação da razão: “Crise de realidade, dirão os cientistas; isso, para o filósofo, significa crise de realismo, crise de imaginação que é, no fundo, uma crise imaginária"13 (BRUNSCHVICG, 1936, p.25).

É evidente que a influência de Brunschvicg sobre Bachelard foi decisiva para a constituição de sua epistemologia. Todavia, há entre os dois algumas divergências. Acompanho, aqui, a posição de Marly Bulcão. De acordo com a professora Bulcão, Brunschvicg, ao defender a transformação da racionalidade, não propõe uma transformação completa, mas somente uma transformação nos modos de raciocínio; o fundamento da razão, a causa de toda a transformação da racionalidade, encontra-se no plano da moralidade. Para Brunschvicg, a razão se transforma enquanto adquire uma consciência moral mais elevada; ela "transita apenas no âmbito das ideias" para que possa desenvolver a consciência moral (BULCÃO, 1994, p.119).

Bulcão defende, por isso, que a razão de que fala Brunschvicg é uma razão contemplativa, uma razão do matemático, e não uma razão que envolve toda a capacidade cognitiva do homem, como propõe Bachelard.

Bulcão afirma que, opostamente à concepção de Brunschvicg,

[a] razão bachelardiana é fundamentalmente trabalho, porque não é um simples espírito voltado para a contemplação passiva do espetáculo do mundo. Afirmar, como Bachelard, que o progresso do conhecimento implica em construção, em retificação, em reorganização, é reconhecer a eficácia da razão ativa, é se insurgir contra a razão ociosa que passivamente adormece na tradição (BULCÃO, 1994, p.117).

Nesse sentido, o racionalismo de Brunschvicg não é um racionalismo aplicado ou um materialismo racional, como é o racionalismo - nesse sentido, bastante original - de Bachelard. É um puro racionalismo, um racionalismo cujo modelo é essencialmente matemático. Isso torna Brunschvicg, em última análise, um platônico. Efetivamente, podemos descobrir também um Bachelard que, expressamente, se diz um realista platônico, especialmente no Essai sur la

\footnotetext{
13 “Crise de réalité, diront les savants; ce qui pour le philosophe signifie crise de réalisme, crise d'imagination, qui est au fond une crise imaginaire".
}

Periódico Horizontes - USF - Itatiba, SP - Brasil - e021045 
connaissance approchée (BACHELARD, 1968) e em La valeur inductive de la relativité (BACHELARD, 2014), que, por serem duas de suas primeiras obras, ainda se encontram sob a forte influência de Brunschvicg.

\section{A (contra-)influência de Bergson}

Outra influência é, num sentido diferente, a dos filósofos contra quem Bachelard argumenta. Esses filósofos podem ser classificados em dois tipos: o primeiro tipo é o dos filósofos que sustentam uma filosofia contrária à ciência, ou cuja concepção de ciência tem um valor negativo; o segundo é o dos filósofos que compreendem o valor da ciência, mas pretendem submetê-la a amarras filosóficas.

Bachelard assim fala a respeito desse primeiro grupo de filósofos:

Desde os primórdios do nosso século, é muito vulgar depararem-se-nos filósofos que parecem apostados em desvirtuar a função da ciência. Incansavelmente, repetem a anedota do feiticeiro que põe em ação certas forças ocultas que depois não sabe deter quando se tornam perigosas. 0 simples fato de pretenderem julgar com uma imagem tão pobre - e tão falsa também - as responsabilidades da ciência prova que se não capacitam de forma alguma de toda a novidade implícita na situação do homem perante a ciência ${ }^{14}$ (BACHELARD, 1952, p.11).

Para Bachelard, Bergson é um exemplo de filósofo que desvaloriza a ciência. Em La évolution créatrice, Bergson afirma que a ciência, seja a antiga ou a moderna, utiliza, necessariamente, um "método cinematográfico": "[a] ciência moderna, como a ciência antiga, procede segundo o método cinematográfico. Não pode fazer de outro modo; toda ciência está sujeita a essa lei"15 (BERGSON, 1959, p.192). O que é esse método? É um procedimento de análise no qual a realidade movente é mascarada pela ilusão da permanência. Toda análise, por

\footnotetext{
14 "Depuis le début de notre siècle, il est fort commun de rencontrer des philosophes qui semblent avoir pris pour tâche de donner à la science une mauvaise conscience. D'une manière inlassable on répète l'anecdote du sorcier qui met em branle les forces cachées sans plus jamais avoir le pouvoir de les remettre au repôs quand les forces déchaînées deviennent pernicieuses. Le seul fait qu'on juge avec une pauvre image - avec une si fausse image - des responsabilités de la science, prouve qu'on ne réalise pas, dans toute sa nouveauté, la situation de l'homme devant la science".

15 "La science moderne, comme la science antique, pro. cède selon la méthode cinématographique. Elle ne peut faire autrement; toute science est assujettie à cette loi".
}

Periódico Horizontes - USF - Itatiba, SP - Brasil - e021045 
sua vez, consiste em exprimir uma coisa em função de outra. Como diz Bergson na conferência Introduction à la metaphysique,

[a]nalisar consiste em exprimir uma coisa em função de algo que ela não é. Toda análise é, assim, uma tradução, um desenvolvimento simbólico, uma representação presa em pontos de vista sucessivos nos quais há bastante contato entre o objeto novo, que se estuda, e os outros, que se crê já serem conhecidos. [...] Assim posto, pode ser visto facilmente que a ciência positiva tem, por função habitual, analisar. Ela trabalha, principalmente, sobre os símbolos ${ }^{16}$ (BERGSON, 1969, p.100).

Isso significa que a ciência, para Bergson, substitui a realidade por signos que podem ser manipulados, signos que têm meramente o papel "de anotar por meio de uma forma bem definida um aspecto fixo da realidade"17 (BERGSON, 1959, p.192), e que, ademais, não revelam a natureza contínua do tempo. Assim, seguindo-se o método cinematográfico da ciência, tomase um instantâneo do filme para analisar o filme inteiro, o que significa fazer um experimento pontual para compreender toda a realidade que se apresenta à consciência como fluxo. Em suma: toda ciência natural, para Bergson, é uma concepção reducionista da realidade vivida não importa se a ciência seja antiga ou moderna, pois não há, entre elas, diferença de qualidade, mas somente de grau: "É o mesmo mecanismo cinematográfico nos dois casos, mas ele alcança, no segundo, uma precisão que não podia obter no primeiro"18 (BERGSON, 1959, p.193-194).

Em outras palavras, a ciência não consegue se aproximar do tempo dessa realidade, que é um tempo contínuo, um tempo em que as interpenetrações das durações não podem ser reduzidas a uma simples justaposição instantânea no espaço (BERGSON, 1959). De acordo com Bergson, o tempo, na ciência, é exatamente uma justaposição instantânea no espaço: não tem duração ${ }^{19}$. Para Bergson, portanto, a física moderna perde de vista a realidade do tempo:

\footnotetext{
16 "Analyser consiste donc à exprimer une chose en fonction de ce qui n'est pas elle. Toute analyse est ainsi une traduction, un développement en symboles, une représentation prise de points de vue successifs d'où l'on note autant de contacts entre l'objet nouveau, qu'onétudie, et d'autres, que l'on croit déjà connaître. [...] Ceci posé, on verrait sans peine que la science positive a pour fonction habituelle d'analyser. Elle travaille donc avant tout sur des symboles".

17 "de noter sous une forme arrêtée un aspect fixe de la réalité".

18 “'C'est le même mécanisme cinématographique dans les deux cas, mais il atteint, dans le second, une précision qu'il ne peut pas avoir dans le premier".

${ }^{19}$ Bachelard discorda das posições de Bergson a respeito do tempo. Se, para Bergson, o tempo é um contínuo, é duração, para Bachelard é instante, e somente pode ser apreendido como tal. Ver L'intuition de l'instant (BACHELARD, 1966) e La dialectique de la durée (BACHELARD, 1936).
} 
O tempo é invenção ou não é nada. Mas a física não pode levar em conta o tempo-invenção, adstrita como está ao método cinematográfico. Ela se limita a contar as simultaneidades entre os acontecimentos constitutivos desse tempo e as posições do móvel sobre sua trajetória. Ela desconecta esses acontecimentos do todo que reveste, a cada instante, uma nova forma e que Ihes comunica algo de sua novidade. Ela considera-os no estado abstrato, tais como seria seriam fora do todo vivo, isto é, num tempo desenrolado em espaço. Ela somente retém os acontecimentos ou sistemas de acontecimentos que podem ser isolados sem que se sofram uma deformação excessivamente profunda, pois somente esses se prestam à aplicação de seu método. Nossa física data do dia em que se conseguiu isolar esses sistemas. Em resumo, se a física moderna se distingue da antiga pelo fato de considerar todo e qualquer momento do tempo, ela repousa inteiramente sobre uma substituição do tempo-invenção pelo tempocomprimento ${ }^{20}$ (BERGSON, 1959, p.199).

A perspectiva científica constitui, para Bergson, uma "metafísica" 21 que não corresponde à nossa intuição; é "uma certa escolástica nova que grassou durante a segunda metade do século XIX em volta da física de Galileu"22 (BERGSON, 1959, p.214).

Bachelard rejeita esse tipo de crítica à ciência moderna (BACHELARD, 1952). De acordo com Bachelard, "[p]ara o julgamento da maior parte dos filósofos de nosso tempo, o racionalismo é uma filosofia pobre" ${ }^{23}$ (BACHELARD, 1972b, p.90); por racionalismo, Bachelard, aqui, entende a filosofia das ciências que busca compreender a prática da própria ciência de um ponto de vista internalista. Bachelard, efetivamente, critica o externalismo praticado "pela maior parte dos filósofos":

\footnotetext{
20 "Le temps est invention ou il n'est rien du tout. Mais du temps-invention la physique ne peut pas tenir compte, astreinte qu'elle est à la méthode cinématographique. Elle se borne à compter les simultanéités entre les événements constitutifs de ce temps et les positions du mobile T sur sa trajectoire. Elle détache ces événements du tout qui revêt à chaque instant une nouvelle forme et qui leur communique quelque chose de sa nouveauté. Elle les considère à l'état abstrait, tels qu'ils seraient en dehors du tout vivant, c'est-à-dire dans un temps déroulé en espace. Elle ne retient que les événements ou systèmes d'événements qu'on peut isoler ainsi sans leur faire subir une déformation trop profonde, parce que ceux-là seuls se prêtent à l'application de sa méthode. Notre physique date du jour où l'on a su isoler de semblables systèmes. En résumé, si la physique moderne se distingue de l'ancienne en ce qu'elle considère n'importe quel moment du temps, elle repose tout entière sur une substitution du temps-longueur au temps-invention".

${ }^{21}$ O termo "metafísica" absolutamente não tem conotação negativa em no pensamento de Bergson; acreditamos que a utilização desse termo para se referir à ciência, no contexto de sua crítica, seja uma ironia em relação às pretensões positivistas.

22 "une certaine scolastique nouvelle qui a poussé pendant la seconde moitié du XIXe siècle autour de la physique de Galilée".

23 "[a]u jugement de la plupart des philosophes de notre temps, le rationalisme est une philosophie pauvre".
} 
Jamais [um filósofo como Bergson] se coloca, para julgar, no fluxo de consciência da ciência; jamais, do lado filosófico, [esse filósofo] adere ao movimento mesmo do progresso efetivo atual da pesquisa científica. É surpreendente que uma polêmica externa sobre o valor da ciência esteja inteiramente fora da apreensão dos valores de pensamento que o racionalismo em ação representa ${ }^{24}$ (BACHELARD, 1972b, p.90).

Bachelard afirma, com alguma ironia, que, para esses filósofos, basta a colocação de um adjetivo para que todo o conhecimento científico seja desprezado, pois o que eles detratam não é a ciência, mas uma caricatura: "[é] contra essa caricatura do racionalismo que se exerce mais comumente a crítica filosófica. Um adjetivo, às vezes, é suficiente. Bergson combate, assim, um 'racionalismo seco'. Ele comumente fala de um racionalismo fixo, esclerosado, cego à experiência concreta" 25 (BACHELARD, 1972b, p.90).

Para Bachelard, filósofos como Bergson - que inventam e combatem espantalhos da racionalidade científica - não podem compreender a ciência, pois não buscam segui-la em sua interioridade. Não percebem que, ao aproximar a racionalidade científica e o senso comum, produzem uma ideia de ciência - mas uma ideia que somente tem validade dentro do mundo restrito de suas teorias filosóficas. Essa é, em suma, a posição dos filósofos daquele primeiro tipo: os filósofos que, devido à má compreensão do que é o trabalho científico, julgam-no de modo completamente equivocado.

\section{A (contra-)influência de Meyerson}

O segundo tipo de filósofos que influenciam Bachelard como adversários é o dos pensadores que valorizam a ciência, mas não a compreendem a partir dos critérios e das categorias da própria ciência. Esses filósofos, para Bachelard, não procuram acompanhar a prática científica; em vez disso, buscam utilizar a ciência como um exemplo da aplicação de suas

\footnotetext{
24 "Jamais l'on ne se met, pour en juger, dans le flux de la conscience de la science; jamais, du côté philosophique, on n'adhère au mouvement même du progrès effectif actuel de la recherche scientifique. II n'est pas étonnant qu'une polémique externe sur la valeur de la science soit entièrement étrangère à la saisie des valeurs de pensée que représente le rationalisme en acte".

25 "[c]'est contre cette caricature du rationalisme que s'exerce le plus communément la critique philosophique. Un adjectif parfois y suffit. Bergson combat ainsi un 'rationalisme sec'. Il est commun de parler d'un rationalisme figé, sclérosé, aveugle à l'expérience concrète".
} 
próprias filosofias. Seu projeto é estabelecer a unidade e eternidade da razão e, por conseguinte, encontrar nas categorias do pensamento a garantia do conhecimento científico - o que significa estabelecer a continuidade entre o mundo do senso comum e o da ciência ${ }^{26}$. Em outros termos, esses filósofos estabelecem critérios a priori de acordo com os quais a ciência necessariamente deve funcionar; esses critérios são concebidos como absolutos e válidos em todas as instâncias do conhecimento. Assim, os filósofos-adversários de Bachelard desse segundo tipo pressupõem (1) a imutabilidade da razão; e (2) a continuidade entre o conhecimento comum e o científico. Um exemplo desse tipo de filósofo é Émile Meyerson. De acordo com Lecourt, que ecoa o julgamento bachelardiano, Meyerson

não negligencia nenhuma das descobertas mais recentes, examina bem tanto as geometrias não euclidianas quanto as teorias relativistas e a mecânica quântica. Meyerson escreveu volume sobre volume, fazendo eco aos eventos científicos mais importantes. Mas foi sempre para sustentar a mesma tese: que o espírito humano procede, em todas as ocasiões, segundo regras que são consubstanciais, e cuja regra principal - senão a única - é a de "reduzir o diverso ao idêntico". Meyerson disputa persistentemente com o positivismo o terreno onde poderia estabelecer, triunfantemente, o reino do espiritualismo. [...] Compreende-se por que Meyerson foi o adversário privilegiado de Bachelard. A polêmica contínua que mantém, livro após livro, contra esse filósofo pode surpreender um leitor do presente onde, na França pelo menos, as teses de Meyerson não são mais conhecidas. Mas falta lembrar que Meyerson era o espiritualista que tentou alistar as ciências físicas ao serviço de uma doutrina à qual, aliás, não lhe demonstraram senão indiferença ${ }^{27}$ (LECOURT, 1974, p.21-22).

Para Bachelard, a filosofia de Meyerson

\footnotetext{
${ }^{26}$ Para Lecourt, esses elementos estão presentes em toda a filosofia clássica ("à l'exception de celle de Spinoza"). (LECOURT, 2002, p.38).

27 "ne néglige aucune des découvertes les plus récentes, examine aussi bien les géométries non euclidiennes que les théories relativistes et la méchanique quantique. Meyerson écrit volume sur volume, faisant écho aux événements scientifiques les plus importants. Mais c'est pour y soutenir toujours la même thèse: que l'esprit humain procède en toute occasion selon des règles qui lui sont consubstantiales et dont la principale - sinon l'unique - est de 'réduire le divers à l'identique". Meyerson s'acharne à disputer au positivisme le terrain où il avait pu sembler un instant triomphant pour y asseoir le règne du spiritualisme. [...] On comprend pourquoi Meyerson a pu être l'adversaire privilégié de Bachelard. La polémique continuelle qu'il mène, livre après livre, contre ce philosophe peut surprendre un lecteur d'à présent où, en France du moins, les thèses de Meyerson ne sont plus guère connues. Mais il faut se souvenir que Meyerson a été le spiritualiste qui a tenté d'enrôler les sciences physiques contemporaines au service d'une doctrine qui, par ailleurs, ne leur manifestait qu'indifférence".
}

Periódico Horizontes - USF - Itatiba, SP - Brasil - e021045 
assenta no mito inquestionado da continuidade da experiência animal e da experiência humana comum, continuidade essa que se prolonga mediante uma continuidade da experiência vulgar e da experiência científica. [..] Lê-se aí [na obra de Meyerson] que um cão bem ensinado se pode considerar sabedor dos rudimentos da mecânica só pelo facto de que apanha "inteligentemente" na boca o pedaço de carne que o dono Ihe atira. Para Meyerson, fica assim demonstrado que o animal possui uma certa noção da 'trajetória'28 (BACHELARD, 1952, p.14-15).

A opus magna de Meyerson é Identité et réalité (1908). Nessa obra, ele propõe-se a demonstrar: (1) que a ciência não deve se satisfazer em enunciar leis da natureza, mas deve explicar os fenômenos, e essa explicação - que vai à realidade subjacente aos próprios fenômenos, sendo, portanto, ontológica - consiste na identificação do antecedente e do consequente; (2) que as teorias atômicas derivam do princípio de causalidade, que se opõe ao irracional; (3) que o princípio de causalidade dá origem ao princípio de conservação; (4) que o princípio de causalidade leva à eliminação do fator tempo na ciência; (5) que mesmo as teorias não-mecânicas derivam do princípio de causalidade; (6) que, portanto, toda a ciência - assim como todo o conhecimento humano - visa a explicar a multiplicidade de fatos singulares por meio de um sistema unitário no qual a totalidade da realidade esteja dada sob o signo da identidade. A posição de Meyerson é, portanto, crítica ao positivismo, segundo o qual a atividade científica não deve buscar as causas verdadeiras dos fenômenos, mas somente suas leis. Ao contrário do positivismo, que procura eliminar a ontologia do mundo da ciência (por meio da concepção que o objetivo da ciência não deve ser o de descobrir as causas dos fenômenos, mas somente leis de relação invariante entre os fenômenos), Meyerson considera que a ciência é, propriamente, ontologia.

Segundo Meyerson, é possível encontrar os princípios das ciências na própria razão (que é uma só, e sempre a mesma): “[e]ssas conclusões não são um resultado da ciência, elas derivam de elementos apriorísticos que ela contém [...]. Defendemos que o mundo do senso comum é criado por um procedimento estritamente análogo àquele que produz as teorias científicas" 29

\footnotetext{
28 "repose sur le mythe indiscuté de la continuité de l'expérience animale et de l'expérience humaine commune, continuité qui se prolongue en une continuité de l'expériencie vulgaire et de l'expérience scientifique. [...] On y verra une page où un chien bien dressé est donné comme sachant les rudiments de la mécanique du seul fait qu'il reçoit 'intelligemment' dans sa gueule le morceau de viande lancé par son maître. Pour Meyerson, il y a ainsi chez l'animal une certaine notion de la 'trajectoire'".

29 "[c]es conclusions ne sont pas un résultat de la science, elles dérivent des éléments aprioriques que celle-ci recèle [...]. Nous établissons alors que le monde du sens commun est créé par un procédé strictement analogue à celui qui produit les théories scientifiques".
}

Periódico Horizontes - USF - Itatiba, SP - Brasil - e021045 
(MEYERSON, 1908, p.XVIII). A razão, mas não a ciência, é a priori: as ciências físicas, por seu turno, se transformam todo o tempo, pois as leis científicas não passam de aproximações mais ou menos adequadas:

A respeito do fenômeno diretamente observado, a lei jamais é senão mais ou menos aproximada; com o uso de correções sucessivas, nós nos esforçamos pra juntar, mais e mais proximamente, a verdadeira marcha da natureza. Mas devese observar que essas novas contribuições modificam sem cessar a ciência existente $^{30}$ (MEYERSON, 1908, p.22).

De acordo com Meyerson, é preciso descobrir as leis científicas, mas é fundamental, em primeiro lugar, ser capaz de encontrar as suas causas. Mas o que é uma causa? Meyerson responde que "[q]uando falamos sobre explicar um fenômeno, de pesquisar as causas, nós buscamos conhecer suas causas, buscamos conhecer sua preexistência no tempo [...] ou a regra empírica que determina sua transformação no tempo"31 (MEYERSON, 1908, p.35).

Sobre a relação entre o senso comum e o conhecimento científico, Meyerson afirma que

[n]ós cremos literalmente, como Le Roy mesmo havia formulado, que a ciência corresponde à mesma atitude do senso comum. Quando esse filósofo nos diz que o cientista fez os fatos científicos e não os fatos brutos, nós estamos igualmente de acordo, porque o fato científico nos parece como referente a um objeto que o cientista criou. Mas [...] ele seguiu exatamente o mesmo procedimento que o senso comum emprega para criar o fato bruto $^{32}$ (MEYERSON, 1908, p.433).

Ou seja: para Meyerson, todas as ciências são movidas pela busca da explicação causal da realidade; essa busca ocorre segundo os mesmos princípios do senso comum; e a meta dessa explicação é, por sua vez, a identificação da unidade e da identidade dos fenômenos.

\footnotetext{
30 "A l'egard du phénomene directement observé, la loi n'est jamais que le plus ou moins approchée; à l'aide de corrections successives, nous tâchons d'en adapter progressivement l'ensemble de plus en plus étroitement à la véritable marche de la nature. Mais il faut observer que ces nouveaux apports modifient sans cesse la science existente".

31 "Quand nous parlons d'expliquer um phénomène, d'em scruter les causes, nous cherchons à connaître soit as préexistence dans le temps [...] soit la règle empirique qui determine son changement dans le temps".

32 "[n]ous croyons à la lettre, comme M. Le Roy lui-même l'avait autrefois formulé, que la science coorespond à la même attitude que le sens commun. Quand ce philosophe nous dit que le savant fait les faits scientifiques et non pas les faits bruts, nous sommes également d'accord, puisque le fait scientifique nous apparaît comme se rapportant à un objet que le savant a crée. Mais [...] il a suivi exactement le même procédé que le sens commun a employé pour créer le fait brut".
} 
Em De l'explication dans les sciences (1921), Meyerson retoma os temas apresentados em Identité et réalité, propondo-se a demonstrar que a ontologia científica, que consiste na busca pela explicação causal dos fenômenos, corresponde à "dedução do fenômeno com base em seus antecedentes, que deverá constituir a consequência lógica"33 (MEYERSON, 1921, p.VII [Tomo I]). No mesmo volume, Meyerson também afirma que "a razão humana, embora antinômica por essência, é, todavia, a mesma em todos os domínios e em todas as épocas"34 (MEYERSON, 1921, p.VIII [Tomo I]). Essas noções são aplicadas por Meyerson ao estudo da Teoria da Relatividade em La déduction relativiste (1925).

A maior convergência entre as posições de Meyerson e de Bachelard sobre a ciência está na proposição de que ciência é propriamente ontologia. Ambos repudiam o positivismo, cuja formulação mais simples corresponde à busca pela descrição das leis correspondentes aos fenômenos, com a rejeição a qualquer explicação de causas últimas - para o positivismo, toda explicação das causas é metafísica - para essas leis.

Todavia, a afirmação de que ciência é ontologia conduz, em Meyerson e em Bachelard, a teses bastante diferentes. Para Meyerson, a ciência é ontológica porque explica as relações causais reais entre o antecedente e o consequente: "todas as explicações [da ciência] são naturalmente, inconscientemente, necessariamente ontológicas"35 (MEYERSON, 1921, p.181 [Tomo II]); para Bachelard, a ciência é ontológica porque cria objetos.

Há outras diferenças entre o pensamento de Meyerson e o de Bachelard. De um lado, Meyerson propõe-se a partir sempre de uma teoria do conhecimento (MEYERSON, 1921, [Tomo I]); de outro, Bachelard recusa a necessidade de fundamentar sua filosofia em uma teoria desse tipo. Para Meyerson, a razão é una e imutável: "ciência e filosofia [...] são, uma e outra, emanações da razão, e de uma razão que permanece fundamentalmente a mesma em suas duas manifestações. E quanto ao senso comum, [...] ele não forma [...] senão um passo no mesmo caminho"36 (MEYERSON, 1921, p.361 [Tomo II]); para Bachelard, ao contrário, a razão se

\footnotetext{
33 "déduction du phénomène en partant de ses antécédents, dont il devra constituer la conséquence lógique".

34 "la raison humaine, tout en étant antinomique par essence, est cependant une, la même dans tous les domaines e à toutes les époques".

35 "toutes ses explications sont naturellement, insconsciemment, nécessairement ontologiques".

36 "science et philosophie [...] sont, l'une et l'autre, des émananations de la raison et d'une raison qui reste fondamentalement la même dans ces deux manifestations. Et quant au sens commun, [...] il ne forme [...] qu'une étape sur la même voie".
}

Periódico Horizontes - USF - Itatiba, SP - Brasil - e021045 
transforma e se desdobra em diferentes racionalidades. Meyerson afirma que os mesmos raciocínios são constituintes do campo do senso comum e do campo da ciência: "[a] ciência, sem dúvida, parte do senso comum" (MEYERSON, 1921, p.183 [Tomo II]); Bachelard rejeita essa tese, propondo a existência de rupturas epistemológicas entre esses dois campos. Para Meyerson, a ciência é dedutiva: a autoridade das teorias científicas, sua "força explicativa", tem a sua origem no procedimento da própria dedução (MEYERSON, 1921, [Tomo I]); para Bachelard, por outro lado, a ciência é indutiva ${ }^{37}$. Meyerson tem uma profunda convicção realista: "nós estamos [...] intimamente convencidos de que a natureza, na mais profunda de suas manifestações, é governada, inelutavelmente, por leis rigorosas"38 (MEYERSON, 1921, p.88 [Tomo I]); Bachelard varia suas concepções - vai de um realismo natural a um anti-realismo, e então a um realismo de segunda posição, que é um realismo científico.

\section{Conclusão}

Bachelard foi, até certo ponto, herdeiro filosófico de Brunschvicg; mas a escolha dos seus adversários - principalmente Bergson e Meyerson - também define os caminhos por onde construiu a sua filosofia da ciência.

A influência de Brunschvicg sobre o pensamento de Bachelard foi grande: seguindo os passos de Brunschvicg, Bachelard conferiu grande importância às matemáticas no "novo espírito científico". Além disso, do mesmo modo que seu professor, procurou descrever o desenvolvimento da razão científica por meio do estudo de casos do progresso científico. Isso acabou lhe mostrando que a razão humana é plástica, é mutável, evolui; o pensamento humano é invenção incessante. É nesse sentido que existe, tanto para Brunschvicg quanto para Bachelard,

\footnotetext{
${ }^{37}$ Embora por indução Bachelard compreenda algo diferente do proposto pela tradição. Vadée diz que "[p]ara Bachelard indução é sinônimo de construção e inclusive de invenção de uma 'realidade científica' pela teoria" (VADÉE, 1975, p.72). Marly Bulcão afirma, nessa direção, que "Bachelard utiliza o termo indução em um sentido que the é próprio e que não foi abordado pelas filosofias ou ciências anteriores. O sentido bachelardiano não é nem o de Aristóteles - que o definia como um método de raciocínio oposto ao silogismo [...] -, nem o de Bacon - que considerava a enumeração como própria do processo indutivo científico -, nem o de Poincaré - que o definia como raciocínio por recorrência. Nenhuma significação de indução pode ser equivalente à bachelardiana. Bachelard considera indução como sinônimo de construção, isto é, como invenção de um real científico. A indução é a construção de fenômenos novos" (BULCÃO, 1994, p.101).

38 "nous sommes [...] intimement convaincus que la nature, jusqu'au plus profond de ses manifestations, est gouvernée inéluctablement par des lois rigoureuses".
} 
uma ruptura epistemológica entre o conhecimento comum e o conhecimento científico.

O embate de Bachelard com a filosofia de Bergson proporcionou a possibilidade de esclarecer e definir as suas próprias posições. Diante da desvalorização da ciência por Bergson, de acordo com quem a o conhecimento científico seria reducionista e substituiria a realidade por signos manipuláveis, Bachelard reafirma a necessidade de seguir a ciência em sua interioridade para compreender corretamente os seus processos.

Finalmente, Bachelard encontra em Meyerson um filósofo que, diferentemente de Bergson, confere um valor positivo à ciência. Todavia, Bachelard aponta que Meyerson falha ao não seguir a ciência a partir do interior do trabalho científico, mas a partir de uma filosofia externa; para Bachelard, Meyerson simplesmente desenvolve um sistema filosófico, com uma teoria do conhecimento que supõe uma razão imóvel, e procura fazer com que a ciência nele se encaixe. Bachelard rejeita, assim, também a teoria da ciência meyersoniana: para Bachelard, o grande erro de Meyerson foi justamente supor uma razão unitária e sempre idêntica.

A influência de um filósofo sobre outro não se dá somente por meio da adesão do segundo às ideias do primeiro. A influência por oposição, a influência por diferença, é tão importante quanto aquela que se dá por convergência e por interseção. De certo modo, Brunschvicg, Bergson e Meyerson foram, os três, mestres de Bachelard: não é outro o sentido da afirmação bachelardiana de que a verdadeira educação exige a atitude de contínua discordância com os mestres. Afinal, "[n]a obra da ciência só se pode amar o que se destrói, pode-se continuar o passado negando-o, pode-se venerar o mestre contradizendo-o. Aí, sim, a Escola prossegue ao longo da vida"39 (BACHELARD, 1970, p.252).

\section{Referências}

BACHELARD, G. La dialectique de la durée. Paris: Boivin, 1936.

BACHELARD, G. Le nouvel esprit scientifique. Quatrième édition. Paris: Presses Universitaires de France, 1946.

BACHELARD, G. L'intuition de l'instant. Paris: Gonthier, 1966.

\footnotetext{
39 "[d]ans l'oeuvre de la science seulement on peut aimer ce qu'on détruit, on peut continuer le passé en loe niant, on peut vénérer son maître en le contredisant. Alors oui, l'École continue tout le long d'une vie".
}

Periódico Horizontes - USF - Itatiba, SP - Brasil - e021045 
BACHELARD, G. Essai sur la connaissance approchée. Seconde édition. Paris: J. Vrin, 1968.

BACHELARD, G. La vocation scientifique et l'âme humaine. In: BACHELARD, G. et al. Recontres internationales de Genève: L'homme devant la science. Neuchatel: Éditions de la Baconnière, 1952, p.11-29.

BACHELARD, G. La formation de l'esprit scientifique: contribution a une psychanalyse de la connaissance objective. Septième édition. Paris : Vrin, 1970.

BACHELARD, G. La philosophie scientifique de Léon Brunschvicg. In: BACHELARD, G. L'engagement rationaliste. Paris: Presses Universitaires de France, 1972a, p.169-177.

BACHELARD, G. Le nouvel esprit scientifique et la création des valéurs rationnelles. In: BACHELARD, G. L'engagement rationaliste. Paris: Presses Universitaires de France, 1972b, p.8999.

BACHELARD, G. La valeur inductive de la relativité: préface par Daniel Parrochia. Paris: J. Vrin, 2014 [1929].

BELAVAL, Y. Léon Brunschvicg. In: BENJAMIN, C. Dicionário de biografias científicas: tomo I. Rio de Janeiro: Contraponto, 2007, p.371-373.

BERGSON, H. Introduction à la metaphysique. In: BERGSON, H. La pensée et le mouvant: essais et conférences. 79e édition. Paris: Presses Universitaires de France, p.98-124, 1969. Disponível em:

http://classiques.uqac.ca/classiques/bergson_henri/pensee_mouvant/pensee_mouvant.html. Acesso em: 12 nov. 2015

BERGSON, H. L'evolution créatrice. 86e édition. Paris: Presses Universitaires de France, 1959. Disponível em:

http://classiques.uqac.ca/classiques/bergson_henri/evolution_creatrice/evolution_creatrice.ht ml. Acesso em: 12 nov. 2015.

BRÉHIER, É. Transformation de la philosophie française. Paris: Flammarion, 1950.

BRUNSCHVICG, L. La physique du vingtième siècle et la philosophie. Paris: Hermann, 1936.

BULCÃO, M. Razão artesã versus razão contemplativa. In: HÜHNE, L. M. (org,). Razões. Rio de Janeiro: Uapê, 1994. p.101-122.

CASTELÃO-LAWLESS, T. Gaston Bachelard et le milieu scientifique et intellectuel français. In: NOUVEL, P. (org.). Actualité et posterités de Gaston Bachelard. Paris: Presses Universitaires de France, 1997, p.101-116. 
CHIMISSO, C. Gaston Bachelard: critic of science and the imagination. London: Routledge, 2001.

CHIMISSO, C. Writing the history of mind: philosophy and science in France, 1900 to 1960 s.

Hampshire: Ashgate, 2008.

DESCHOUX, M. La philosophie de Léon Brunschvicg. Paris: Presses Universitaires de France, 1949.

FREIRE, O. A física dos quanta e o "novo espírito científico". Reflexão. v.62, n.1, p.38-57, 1995.

GUTTING, G. French philosophy in the twentieth century. Cambridge: Cam-bridge University Press, 2001.

KUHN, T. A estrutura das revoluções científicas. Trad. Beatriz V. Boeira e Nelson Boeira. 5. ed. São Paulo: Perspectiva, 2000.

LECOURT, D. L'épistemologie historique de Gaston Bachelard. Paris: Vrin, 2002.

LECOURT, D. Le jour et la nuit: un essai du matérialisme dialectique. Paris: Bernard Grasset, 1974.

MEYERSON, É. Identité et réalité. Quatrième édition. Paris: Félix Alcan, 1908.

MEYERSON, É. De l'explication dans les sciences. 2 tomos. Paris: Payot, 1921.

MEYERSON, É. La déduction relativiste. Paris: Payot, 1925.

VADÉE, M. Bachelard ou le nouvel idéalisme epistemologique. Paris: Éditions Sociales, 1975.

WAHL, J. Tableau de la philosophie française. Paris: Gallimard, 1962. 